\title{
JOHN V. MURRA, ACTOR (ODESSA 1916-ITHACA, NY 2006). LA RETÓRICA DE LA EXAGERACIÓN ${ }^{1}$
}

\author{
Tristan Platt ${ }^{2}$
}

Me acuerdo de mi primer encuentro con John Murra. Fue en Ithaca, New York, en el verano de 1969, cuando él tenía 53 años y yo 24. Él había llegado a Cornell University el año anterior. Yo tomaba un curso de verano con el lingüista y quechuista Don Solá, antes de volver como doctorando a Bolivia, a donde había ido de inocente pre-universitario por nueve meses en 1963. Fue un verano memorable.

Yo nunca fui estudiante matriculado de Murra, pero encontré su orientación insustituible después de los estudios antropológicos de Africa, India y Melanesia que había conocido en la London School of Economics durante los dos años anteriores. Murra hablaba, con total convicción proselitista, desde dentro de algo que llamaba los "estudios andinos"; y noté desde el principio que utilizaba el pronombre "nosotros" -no el nosotros de autoría, ni menos el nosotros "real"-, pero como miembro de una "comunidad andina" de investigadores antropológicos (1970-71).

En quechua, se distingue el "nosotros incluyente", que abarca a la persona a quien se dirige, del "nosotros excluyente", que contrasta el grupo de referencia del que habla con el de la persona oyente. Pero el "nosotros" de Murra tenía otra nuance: señalaba una comunidad en proceso de gestación, a que quizás no pertenecía su interlocutor todavía, pero que estaba lista a recibirle. Quizás podríamos hablar del "nosotros de la construcción etnogenética" ... Quizás la comunidad a que se refería nunca existió salvo en la imaginación de John; pero muchos participarían felices en su sueño.

En boca de Murra, este "nosotros" pro-activo decía (y me acuerdo de sus palabras): Tenemos lugar para todos, para etnobotánicos, ingenieros hidráulicos, agrónomos, arqueólogos, tejedoras, historiadores, poetas, etnógrafos, músicos, artesanos, todos pueden aportar con su especialización a avanzar el conocimiento de un milagro: el milagro logrado por una civilización que debía, diría, poco o nada a otras regiones del mundo, que era diferente de los demás, siendo uno de los 5-6 centros de "civilización prístina" en el mundo ... ¿Cómo la gente de los Andes había logrado (el "logro de lo andino" fue otra frase clave suya, que más tarde provocaría la ira mal-dirigida de los "anti-esencialistas") una producción tan abundante, una civilización tan sofisticada, en zonas tan inhóspitas, tan únicas en el mundo, como la puna y el altiplano de este enorme sistema montañoso tropical? ¿En alturas donde el aire es tan fino que la temperatura cambia más cada 24 horas que en cualquier otra parte del mundo?, reemplazando los cambios climáticos estacionales que se conocen en las latitudes templadas con un cambio climático diurno (y aquí citaría a Carl Troll)? ¿Cómo esta gente lograba, en condiciones tan violentas, tanta densidad de población? y ¿que nadie muriera de hambre? ¿Cómo habían manejado un sistema fiscal tan preciso, y a la vez tan flexible, que podía tomar en cuenta las condiciones cambiantes de cada comunidad, en cada región, de un año a otro (algo que después los indios reclamarían en vano de Su Majestad)? ¿Cómo habían logrado que la gente, por lo menos en aquellas regiones donde los Incas eran más aceptados, fuese bailando y cantando a trabajar en los terrenos del Estado? ¿Era la Utopía de Tomás Moro? ¿Era un "socialismo pre-industrial", tal como había sugerido (desde la derecha) Louis Baudin?

La respuesta de John era otra. Pero para comprenderlo, diría, hacía falta la colaboración de muchos especialistas, además de comparaciones con los trabajos antropológicos en Africa y Melanesia; y todos juntos eran el "nosotros" que ofrecía a los que paseaban, desprevenidos, delante de su tienda en el mercado académico: la comunidad de estudiosos antropológicos del "milagro" andino. (Siempre decía que, para acercarse a cualquier ciudad, había que empezar con su mercado...).

\footnotetext{
1 Sesión conmemorativa para JV Murra, École des Hautes Études en Science Sociale, Paris, 25 enero 2007. Acto homenaje a John V. Murra, Institut d'Estudis Catalans, Barcelona, 20 de febrero de 2007, Institut d'Estudis Catalans, Barcelona.

2 University of St. Andrews, St. Andrews, Scotland. tp@st-andrews.ac.uk
} 
Murra adoptó mi proyecto de investigación desde el principio. En 1970-71 envió cartas y comentarios frecuentes y detallados sobre mis informes de campo enviados desde Bolivia. Me iba acostumbrando a una regularidad de correspondencia al viejo estilo. Era evidente para mí la diferencia y la utilidad de tener a alguien como él como lector de mis escritos. En Inglaterra, en aquel entonces, apenas hubo antropólogo andinista (aunque no quisiera subestimar el apoyo del especialista en Nueva Guinea Anthony Forge, en aquel momento mi supervisor "oficial"). Murra percibió de inmediato, por ejemplo, la relación entre las batallas rituales -los famosos tinkus - y los procesos de legitimación del acceso de los grupos participantes a la tierra. Y así, me invitaba a participar en el número pionero de la revista francesa Annales ESC de 1978, donde (como el diría) "íbamos poniendo la tienda" de los nuevos estudios andinos para la gran comunidad historiográfica articulada por Annales.

Murra dedicaba cada mañana a su correspondencia. Daba noticias a sus corresponsales sobre otras investigaciones en curso en diferentes partes de los Andes y del mundo, sobre sus conversaciones con colegas, sus proyectos, sueños y frustraciones. Nos iba haciendo partícipes en esa red de chismes profesionales que poco a poco llegaba a ser un marco de referencia insustituible, un contexto a la vez académico, social y político. Nos quería incorporar en su gran proyecto, como intelectuales militantes por la causa andina. Mantenía una correspondencia con un vasto abanico de gente, como puede verse en el catálogo de sus papeles que ahora están en la National Anthropological Association del Smithsonian Institution en Washington DC.

La etnografía que yo le describía desde el gran ayllu de Macha, en el Norte de Potosí, entonaba con algunas de sus propias preocupaciones, sobre todo con respecto a la organización en vivo de la forma de asentamiento que él bautizaba como el "archipiélago vertical". Antes de salir de Cornell en 1969, él ya me había dado los gráficos de los Chupaychu y de los Lupaqa que después se publicarían en su famoso artículo sobre la "verticalidad" de 1972. Este patrón se formaba en regiones que él llamaba "multi-étnicas", compuestas por grupos de colonos (mitimaes) situados en tierras lejanas de los centros de poder-que se ubicaban en otras alturas del sistema montañoso-, y muchas veces dentro del dominio de otro poder local. Como inmigrante rumano-judío a los EE.UU., Murra tenía un interés personal en los problemas de los mitimaes, palabra traducida por Guaman Poma como "forasteros" ... Pues, lo que yo encontraba en los valles del Norte de Potosí fue precisamente eso; y pronto encontraría en el Archivo Nacional de Bolivia (Sucre) la primera documentación que demuestra su antigüedad. Durante mucho tiempo mi propia vida profesional estaría marcada por esa "coincidencia dirigida".

Pero además, yo fui criado por mis padres desde pequeño para respetar a los actores y los músicos, $\mathrm{y}$ disfrutar del buen teatro. $\mathrm{Y}$ he disfrutado mucho observando los talentos histriónicos de John, que son inseparables de su mensaje. Pude observar sus actuaciones brillantes y fascinantes en escenarios variados, sobre todo latinoamericanos, a lo largo de los años 1970 y 1980. Me parece que, para entender su pensamiento, es importante recordar los gestos y la retórica que desarrolló para divulgar su visión y sus ideas. Así que es como actor de sus propias obras, o (como él diría) "cantante de sus propios tangos", que quiero conmemorarlo hoy con ustedes.

Murra fue un conferencista de una calidad excepcional, una estrella del podio universitario. Pocos quienes han presenciado sus grandes performances en los paraninfos de las universidades latinoamericanas van a olvidarse de ellos. También escribió en varios idiomas, y sus escritos son una parte importante de su herencia, aunque era perfeccionista y, como a muchos, le costó escribir: algunos textos tardaron años, y otros (como la investigación sobre el juez andinófilo del siglo XVI el Dr. Manuel Barros de San Millán, que le obsesionó durante los últimos años de su vida) nunca fueron completados. Pero cuando hablaba frente al gran público, pudo explayarse y jugar con sus audiencias, de manera que él también encontró recursos imprevistos de expresión. Fue en esas grandes sesiones públicas cuando pudo encantar e intentar movilizar a sus oyentes en apoyo de la "causa andina".

En esas exposiciones, a veces se invertiría la situación que él mismo había vivido en las aulas de Chicago durante los años treinta, cuando asistía a las clases de A. R. Radcliffe-Brown. Solía contar cómo, desde el fondo del aula, gritaba a RadcliffeBrown, después de las exposiciones tranquilas, racionales y desprendidas de este científico inglés, “YY qué pasa con la lucha de clases?” Ahora, en América Latina durante la década de 1970, se invirtió la relación. Ahora fue a él a quien los estudiantes revolucionarios de los años setenta solían gritar “¿Y qué pasa con la lucha de clases?”Y me 
acuerdo cómo, en una ocasión en la Universidad Mayor de San Marcos de Lima, donde compartía el podio con Lucho Lumbreras y Aníbal Quijano, se iba impacientando hasta estallar con la respuesta: "Señores - estamos aquí - para aprender - algo NUEVO ... !" Silencio general.

En septiembre de 1971 volví de Macha pasando por Ithaca, y hablé de los grandes ayllus del Norte de Potosí en un seminario informal realizado en el jardín de su casa de Dryden Road. Y en 1972, de nuevo en Londres, le escribí que, después de leer los dos ensayos sobre su tesis que escribió Maurice Godelier, poniendo de manifiesto el trasfondo marxista que tuvo que esconder en los EEUU del senador McCarthy, la tesis ahora me parecía de alguna manera diferente. Murra me contestó diciendo que Godelier había sabido reconocer algo en la tesis que otros habían pasado por alto, y señalando el espacio liberador que significaba el "modo de producción asiático" para los historiadores y los antropólogos de Europa Oriental, demasiado constreñidos por la secuencia unilineal del dogma estalinista (Por otra parte, cuando le comenté la posible relevancia de Lenin para una comprensión de su tesis, me contestó bruscamente que Lenin no tenía nada que ver con el asunto).

¿Como describir sus performances en Perú, Chile, Argentina, Ecuador, Bolivia y México? En la contratapa de un libro recién salido en Lima sobre las relaciones que antes unificaban el centro-sur andino, Heather Lechtman, la que fue su primera estudiante en Vassar College antes que él se trasladara a Cornell y pionera de la investigación de la metalurgia andina, hizo imprimir las siguientes palabras de Murra:

El logro de lo andino es combinar en un solo sistema cosas muy distintas. Hay una tendencia en las ciencias sociales y humanas a reducir siempre las diferencias. Y hay otra posición, que es la mía, de querer enfatizar y hasta exagerar el logro de lo andino. La antropología es la ciencia de las diferencias. Mientras que la ciencia, en general, es la ciencia de las uniformidades. Y lo nuestro no. Lo nuestro es un canto de la diferencia [énfasis mío].

Se nota el ritmo oral del párrafo: insiste sobre el problema de reconciliar políticamente la diferencia con la unidad, algo que sugiere que se había resuelto, por lo menos en parte, en los Andes. Volveré sobre el tema de la exageración-además del gesto, el timing, la variabilidad de tempo y volumen, la metáfora improvisada- que, como los estudiantes parisinos de 1968, él reconoció como una poderosa arma retórica.

La diferencia era efectivamente una de sus enseñanzas más liberadoras en aquellos tiempos -años antes que llegara a ser la consigna de los post-estructuralistas. Murra animaba a todo(a)s a que encontrasen sus propias voces, y que se fueran produciendo una infinidad de perspectivas sobre los Andes, aunque fueran orquestadas y articuladas (por lo menos en parte) por sus propias prioridades investigativas. Solía comentar cómo tal o cual persona tenía que hacer su propio camino, a pesar de que, para hacerlo, había tenido que apartarse de la ruta que él, Murra, hubiera querido sugerirle ...

¿Cómo era su "canto de la diferencia"? Aquí se dirigía al "logro" de los pueblos de los Andes $\mathrm{y}$, a pesar de todas las críticas dirigidas en contra del supuesto "esencialismo" de su concepto de "lo andino", predicaba una manera de percibir los Andes como un mundo dinámico, histórico, de diferencias y transformaciones que se habían orquestado por un "orden": el orden del Inca; y siguiendo, como diría, a Cieza de León, a Polo Ondegardo o a Domingo de Santo Tomás, nunca cansaba de explorar, analizar y asombrarse delante de él. Exagerando, cantando, susurrando, seduciendo, hipnotizaba a sus audiencias con el brillo de sus grandes ojos, y la sonrisa del actor experimentado, capaz de encantar y fascinar con el atrevimiento de su retórica, y sobre todo por lo diferente de su manera de ver los problemas antropológicos, que en sus manos trascendían los discursos de las academias, y se volvían herramientas potentes para formar una nueva política, de soñar un nuevo mundo. "Es que parece que yo ofrezco una esperanza", me decía una vez, para explicar su propio éxito. Pues sus enseñanzas nunca eran puramente formales y abstractas, ni tampoco eran denuncia política, como comúnmente se escuchaba en aquel tiempo: estaba al acecho de todas las voces, de todas las diferencias (para parafrasear el título de una novela de su amigo y colega, el poeta, escritor, antropólogo y quechuista peruano José María Arguedas).

La existencia de una conexión entre la situación de la gente andina en los años setenta y la de la gente del siglo XVI fue un acierto a priori de su enfoque histórico; pero a la vez fue un descubrimiento paulatino. La pista hacia el presente fue dada ya por 
sus tempranas visitas al Ecuador; por su amistad y colaboración con Arguedas, y con José Matos Mar y Heraclio Bonilla, con quienes -entre otros-fundó el Instituto de Estudios Peruanos a inicios de los años sesenta, que combinaba "todas las disciplinas"; y en los años ochenta con Carlos Sempat Assadourian, otro pionero de la unidad y las diferencias andinas, pero ahora a partir de la circulación de la moneda colonial entre diferentes espacios y regiones. Se reforzaba también mediante la enseñanza, como en la Maestría en "Historia Andina" de FLACSO-Quito (1985) -“nuestra Maestría”, como él diría después-, entre muchas otras ocasiones. Y ya en el proyecto que dirigió en Huánuco -de donde surgió el famoso "Cuadernos de Investigacion I" (1966), que nunca tuvo sucesores- buscaba combinar la arqueología de los sitios incaicos con la orientación dada por la documentación de las Visitas de Huánuco, y con la nueva etnografía de jóvenes vinculados con los Andes, como Enrique Mayer y César Fonseca Martel. Fonseca, por ejemplo, trabajando con él en Huánuco y combinando su propia socialización andina con la lectura de las Visitas, pudo detectar fenómenos actuales y a la vez muy antiguos de intercambio y articulación entre diferentes esferas de circulación (me acuerdo que John señalaba su análisis del unay precio, el "antiguo precio" del maíz, o tasa tradicional de intercambio, que los indios mantenían al margen del mercado; y el margen de ganancia que esto ofrecía a los especuladores mestizos, que controlaban el acceso al mercado regional y nacional).

Los años setenta eran, por un momento de ilusión, la década del descubrimiento que las sociedades andinas, en muchas regiones, habían podido persistir -cambiadas, mutiladas, transformadas, mercantilizadas, reinventadas, colonizadas-, pero invitándonos a hacer la historia antropológica de su experiencia compleja, abigarrada, violenta, enterrada durante 450 años. Durante toda esa década Murra iba por los Andes con su canto de la diferencia, buscando a la gente que le escuchara. Buscaba la arqueología, la historiografía y la antropología, la literatura y los intelectuales de cada país, pero reservaba un trato especial para la "gente andina". Y ahí llegó, finalmente, a Bolivia ("tienes razón, ahí está la gente", me decía; y después, "lo único que temo es que, cuando lleguen al gobierno, pueden estar con tanta rabia ..."). Me acuerdo cómo en 1982-83 se quedaba varios meses en La Paz, a invitación de Hugo Daniel Ruiz, en aquel entonces Director del Museo
Nacional de Etnografía y Folclore (MUSEF). Fue en La Paz que conoció a su equivalente boliviano en el tema de la complementariedad ecológica, Ramiro Condarco Morales, a quien después invitaría a Cornell. Y en Sucre conoció a Gunnar Mendoza, el eximio Director del Archivo Nacional de Bolivia, con quien trabó una relación de respeto y amistad mutua al punto de pensar jubilarse en Sucre (donde había vivido también su maestro en asuntos andinos, Polo Ondegardo, además de su alter ego, el Dr. Barros). Trabajar con los intelectuales de cada país era parte de la antropología que predicaba; a veces diría que había tantas antropologías como países, pueblos e incluso individuos ...

De ahí que la antropología profesional del Atlántico Norte no tenía por qué ser la más interesante para todos; a veces, incluso decía que cada individuo debería inventar su propia antropología. Y en sus clases sobre la historia de la antropología norteamericana enfatizaba, precisamente, el movimiento de individuos entre grupos y ambientes, entre diferentes experiencias y perspectivas. Sobre Paul Radin, por ejemplo, dijo que "supo la no-solidez, la no-rigidez de la cultura. [Radin] critica a Kroeber, Sapir y Benedict, los etnógrafos más individualistas, por solo estar dispuestos a reconocer a los individuos cuando han sido pre-clasificados ["pre-pegged"] como procedentes de alguna cultura". Porque para Murra la experiencia individual era el punto de partida: "la [mejor] antropología es una manera de vivir con una identidad étnica no-resuelta". De ahí que la experiencia personal de la diversidad proporcionaba una base más sólida para la antropología que cualquier "distancia" conceptual procedente de la teoría ${ }^{1}$. En otra ocasión, le escuché decir que "la teoría es algo que uno aprende de joven"; después, es la experiencia la que enseña ... Leyendo estas frases, es evidente que decir que Murra fuera "esencialista" es una simple tontería.

Así, la vida y obra de John eran una paradoja: por una parte animando la colaboración en torno a un conjunto de ideas y la búsqueda de nuevas fuentes claves, y por la otra promoviendo la diferencia, la fragmentación y la falta de homogeneidad en las perspectivas de los investigadores. La misma paradoja subyace en su paso desde una teoría general del Tawantinsuyu hacia una creciente absorción en las situaciones y las vidas de individuos poco conocidos: un curaca mercader de vinos de Moquegua, que tenía a su apoderado español en Potosí; un grupo de cocaleros donde el conquistador Alonso 
de Alvarado tenía su encomienda en las yungas de La Paz; el juez andinófilo Dr. Barros, quien se arriesgaba a oponerse al virrey Toledo, y recibía a los indios en la cocina de su casa en La Plata (la cocina para John era siempre el centro de la casa), además de dejar que sus esclavos negros anduviesen por la casa "como si fueran libres", para escándalo de sus enemigos como el oidor de Charcas, Juan de Matienzo.

De esa manera, John pedía la lealtad, pero al mismo tiempo dificultaba la cercanía. Podía entusiasmar como nadie a sus estudiantes, y el próximo momento ahuyentarles con una impaciencia feroz frente a un desliz o una palabra que le pareció tonta, conformista o malograda. Se hizo muchos enemigos, y también algunos amigos incondicionales. Esta dinámica fue fuerte y provocó conflictos; al mismo tiempo, los que supieron aprender de él sin huir de sus broncas ni dejarse herir por sus salidas, se premiaban con una fuente inagotable de enseñanzas y entretenimientos que despertaban el afecto y la gratitud.

La participación en las Brigadas Internacionales durante la Guerra de España, por ejemplo, fue una experiencia que cambió el rumbo de su vida, provocó el abandono de la política y le devolvió a la vida intelectual. Pero le dejaba con una fascinación duradera con los intérpretes (había sido intérprete en Albacete, por su asombrosa capacidad de lenguaraz), y también con la organización de los ejércitos: de cómo era necesario preparar el equipamiento, los pertrechos, la alimentación, y toda la logística de la guerra, y la gente de apoyo y servicio detrás de la movilización militar, algo que después transfirió a sus intentos de comprender el funcionamiento de los ejércitos incaicos: los silos y los almacenes, el chuño como comida de campaña, los tambos y los caminos, las recuas de llamas que acompañaban a las tropas, la contabilidad de los quipos ... Eran las piezas que, juntas y en su articulación, se traducían en una pre-condición importante del orden que buscaba comprender, a la vez que lo expresaban. En su contribución al número andino de Annales (1978), hablaba del desarrollo del ejército incaico, desde una colección de comunidades de campesinosguerreros, que se ausentaban de sus faenas agrícolas y debían volver a ellas; después vino la elección de ciertos grupos privilegiados de élite (como los Qaraqara y los Charka, y otros llamados "soldados del Inca"), nutridos por el Estado con chuño, chicha y mujeres durante las campañas de Quito y Pasto, pero que eventualmente volvían a sus hogares, sus caudillos premiados con regalos, princesas y nuevos apodos honoríficos; y, finalmente, la elección de dos grupos especializados que reemplazaron a éstos, los Cañaris y los Chachapoyas, que llegarían a ser soldados profesionales que vivían enteramente a expensas del Estado, pero eran los primeros en traicionar a los Incas cuando llegaban los Pizarro y su gente, para imponer una nueva "propuesta" de patrocinio estatal.

El "orden" del Inca ... Fue la fascinación de Murra con este orden, su conciencia de lo que había hecho posible, y de la bruta estupidez con la cual había sido destrozada (a pesar de la presencia de algunos españoles tan perspicaces e inteligentes como Polo Ondegardo), la que llegaba a ser su "tango" constante, y le llevaba finalmente a enfatizar más la arqueología que la etnografía, o la historia documental: "la arqueología debe complementar a los historiadores con la verificación sobre el terreno de sus hipótesis", solía decir. Para él, todas eran "tácticas" (otra palabra favorita) que se debían combinar para lograr el objetivo antropológico común: la comprensión del Otro. Nunca se cansaba de denunciar lo que se había perdido con la "invasión europea" (como solía llamarla, reservando la palabra "conquista" para la expansión incaica), ni de insistir que sólo la arqueología iba a responder a las preguntas más importantes sobre el Tawantinsuyu; y esto en sí le marginaba de muchos debates antropológicos académicos.

Y fue su insistencia sobre la diferencia, sobre la unicidad de la experiencia andina, que le llevaba a sostener que los campesinos bajo el Inca "no pagaron tributo": sólo contribuían con sus energías, su fuerza de trabajo, en tierras del Inca, utilizando las herramientas y las semillas proporcionadas por el mismo Estado. Fue otra exageración, como sus críticos rápidamente señalaron; pero una exageración que le parecía necesaria para enfatizar el resultado que llevaba a miles de campesinos a ir bailando y cantando a ocuparse de las faenas de la producción estatal, algo impensable bajo los Estados europeos, y mucho menos bajo el régimen soviético... ¿Qué idea de "trabajo" tenía esta gente?

Murra cambiaba mucho en su manera de ver las cosas, en los tipos de problemas que le interesaban, desde 1955 cuando terminaba su legendaria tesis, que utilizaba los conceptos de redistribución y "generosidad institucionalizada" que asociamos con el nombre de Karl Polanyi (después Murra diría que 
había desarrollado esta idea independientemente, en convergencia con Polanyi) para echar luz sobre la economía política del Tawantinsuyu, y que por años circulaba entre un pequeño grupo de interesados, sin que él se sintiera capaz de publicarlo. Con esa tesis culminó un largo proceso terapéutico con Saul Newton, el sicoanalista a quien agradecía en el prólogo y a quien había conocido en España; pero poco después de defenderla había encontrado nuevas fuentes burocráticas, las Visitas que la pionera andinista francesa Marie Helmer había señalado desde la década de 1920, y que cambiaría nuevamente su rumbo intelectual y el de todos los que se dedicaban a los estudios andinos.

Años antes de que los estudios post-estructuralistas empezaban a hablar de la "agencia" entonces, o que se preguntaba desde los estudios subalternos "si la subalterna pudiera hablar", Murra estaba empeñado en recuperar las voces y las estrategias negociadoras y adaptativas de los "señores naturales de la tierra" y de la gente común frente a las imposiciones de "la invasión europea". Y es por eso, quizás, que, para los estudiosos de los Andes, la reciente notoriedad de los estudios subalternos hindúes y africanos, y el desarrollo de los estudios post-coloniales, despiertan una leve sensación de déjà $v u$, como si se estuviera planteando algo que hace tiempo era parte del medio ambiente en que se desarrollaban los estudios andinos bajo la influencia de John Murra.

Quiero volver, entonces, a su "canto de la diferencia", a su habilidad con la palabra, a la facilidad con que hablaba francés, inglés, castellano, alemán, ruso, rumano, italiano y otros idiomas; a sus grandes ojos saltando de su cara con entusiasmo y chispas de travesura; y a los juegos de seducción y asombro con que alucinaba a sus audiencias. Déjenme dar algunos ejemplos más de su exageración:

1. El logro de las obras hidráulicas: de un golpe enfatizaba la primacía tecnológica de las culturas hidráulicas de la costa Norte, atribuyéndoles la capacidad de construir un canal a través del istmo de Panamá. Los del istmo decían (decía) que más al sur había gente que sí sabría hacerlo, porque sabían obedecer ... Claro que aquí estamos hablando de la gente que sabía unificar los caudales de 4-5 valles costeros con canales que permitían transferir el flujo del agua del cauce de un río a otro, según necesidad -algo que no se ha vuelto a lograr hasta el día de hoy. Por otra parte, Murra planteaba el debate con
Wittfogel, argumentando que las grandes obras hidráulicas y monumentales podían hacerse por comunidades o jefaturas trabajando en conjunto, sin que sea necesario recurrir al modelo del estado hidráulico, algo que Richard Burger después recuperó y demostró. Y los ingenieros hidráulicos han mostrado cómo se variaba el cauce y la inclinación de los canales, aumentando y retrayendo el flujo de las aguas, jugando con las presiones y los estancamientos para superar los obstáculos, dotándolas de la fuerza necesaria para mantener su rumbo. Pero, ¿podrían haber hecho un canal de Panamá?

Curiosamente, experimenté la misma sensación de vértigo frente a capacidades impensables procediendo de la gente andina en el Norte de Chile, cuando me dijeron algunos campesinos de Pampa Algodonal, en las cabeceras desérticas del valle de Azapa, que sabían hacer que el agua suba de altura. “Cómo?!” les dije; y su respuesta, "lo que pasa, señor Tristán, es que el cerro no es redondo ..." O sea, llevando el agua por esta ladera y por esa quebrada y sacándola por aquel punto y por esa pampa, se podría terminar en un nivel más alto que el punto de partida. A veces pienso que he dejado demasiadas preguntas pendientes allá en Pampa Algodonal ...

2. Otro ejemplo: el "logro" de secar por congelamiento, aprovechando de aquellas condiciones únicas donde las variaciones de temperatura en cada 24 horas son más violentas que en cualquier otra parte del mundo ... Así se elaboraba la papa secada, congelada, liviana y duradera que se conoce como chuño; y Murra llevaba a Cornell al aymara-hablante Mauricio Mamani, después Ministro de Asuntos Campesinos de Bolivia, a exponer los detalles prácticos de esta tecnología en aquel entonces poco comprendida en la academia norteamericana.

En una ocasión, su atrevimiento casi coqueto salió en la forma de un reto a un General de Ejército chileno presente en una conferencia dictada en Arica en 1975, en plena dictadura militar; pues, para John era importante defender lo andino contra cualquier gobierno, tanto las privatizaciones neo-liberales de Pinochet como los colectivismos de las reformas agrarias socialistas. Así, buscando una manera de explicar la importancia del chuño en la civilización andina, echó mano a la metáfora del guante, metáfora que le escuché utilizar en más de una ocasión: "Veo aquí a un General de Ejército. Ud., señor General, estará de acuerdo conmigo si digo que 
es imposible poner un ejército en campaña sin un buen sistema de apoyo alimentario y logístico". Lo que pasa-seguía- es que los campesinos andinos han tomado las condiciones hostiles, agresivas, de las altas punas, donde nadie hubiera sospechado que era posible sobrevivir ... y como si fuera un guante, lo han invertido [haciendo el gesto físico de sacar el guante con la cara interna para afuera], y así lo han convertido en una fuente de abundancia y prosperidad, logrando [otra vez la palabra "logro"] que haya comida -incluso el chuño, precisamente, vituallas duraderas para el ejército-, y sobreproducción para todos, excedentes que se acumulaban en los almacenes familiares, étnicos y estatales, y también se extraían por un Estado que reconocía las diferencias, tomando en cuenta los años malos en esta comunidad y los años buenos en otra comunidad, calibrando producciones, tomando porcentajes de las poblaciones para que sirvan de mitayos, o trabajadores de turno, y registrando los resultados en sus quipos: el "orden", pues, que se había quebrado, como un vaso de vidrio lleno de riqueza inimaginable, debido a la invasión europea.

3. Me acuerdo también de su simple letanía, repetida muchas veces mientras viajábamos en Toyota en 1978 entre Oruro y Sucre por el camino que pasa por las minas de Siglo XX y Uncía, y después por Pocoata y Macha, con las altas tierras de larga rotación, los mantas o aynuqas de la agricultura altoandina, visibles en las laderas siempre más altas y empinadas que se yerguen en cada lado del camino, terrenos que han descansado más de 20 años hasta volver a estar en condiciones de fertilidad. “ ¡Están locos! ¡están locos!”, dijo en voz baja mirando por la ventana del jeep; y después, con una sonrisa: "Yo hablo de esto todo el tiempo, pero cuando lo veo ..." No sé si estaba queriendo convencerse a sí mismo y a sus oyentes de su propio asombro; pero como buen actor terminó asombrando a ambos.

4. O la frase que Frank Salomon ha tomado como epígrafe para su reciente libro sobre los khipus de Tupicocha: "No hay que decir 'perdido', hay que decir 'todavía no encontrado"'. Yo me acuerdo cuando John me dijo que había decidido que era mejor usar esa fórmula, tratándose de fuentes y conocimientos que no podíamos localizar. Siempre era posible, reuniendo esfuerzos, combinando disciplinas y "tácticas", recuperar lo que había desaparecido, descubrir documentos perdidos, leer entrelíneas a los textos existentes y reconocer, en términos antropológicos, algo que quizás pudo compararse con Africa, con Polinesia, con México, pero que terminaría siempre escapando a los modelos importados desde otras partes del mundo para dejarnos callados con su simple unicidad. Incluso los quipos pueden volver a soltar su poesía ...

5. O el título que eligió para un texto que reconocía el éxito de algunos grupos andinos al recuperar, en la década de 1570, una parte del exceso de valores extraídos en 1548-51 por los encomenderos del reparto de La Gasca, antes de la llegada de la tasa oficial en 1552. Su "amigo", el andinófilo Dr. Barros, juez en la Audiencia de Charcas durante los años 1570 y 1580, había dado permiso a los indios de Sacaca, cabecera de la antigua federación de los Charka, a traer sus quipos a declarar en las cortes, ordenando que se aceptara su evidencia, porque "los quipos son sin fraude ni mentira". Murra, triunfante, escribía: "los quipos prevalecen en las cortes"; una exageración que los autores hemos mantenido en la presentación a la transcripción del mismo texto en nuestro libro Qaraqara-Charka ${ }^{2}$.

De hecho, la mejor charla que le escuché dar sobre el Dr. Barros fue durante su visita a la Universidad de St. Andrews en 1990, a donde yo le había invitado como profesor visitante para dar el pretexto de un "fortnight andino". Él pasaba dos semanas en la Universidad escocesa; y allá encontró, de sorpresa, la hospitalidad y complicidad de un compañero de lucha en las Brigadas Internacionales, el profesor escocés Douglas Gifford del Departamento de Español, con quien pasó horas de reminiscencias, como me ha recordado una estudiante de Douglas, la quechuista y sociolingüista Rosaleen Howard.

6. Finalmente, les doy el ejemplo del mismo archipiélago vertical como exageración retórica. Aquí está su formulación más abierta y dinámica, que sin embargo ha despertado años de polémica entre los estudiosos:

"Es tentador predecir que tal 'control vertical de un máximo de pisos ecológicos' no se refiere simplemente a una sola etnia, sino a una red de contradictorios reclamos, ajustes temporales, tensiones, luchas y treguas entre varios núcleos regionales que compartían un mismo ideal en una etapa preparatoria a los 'horizontes' del arqueólogo".

Aquí se encuentra la clave a su propia retórica. La metáfora del "archipiélago vertical" es dramática, 
geográfica, inolvidable; remite a la relación entre la diferencia (étnica, y a veces individual) y la semejanza (ideal compartido); ha orientado las investigaciones de agrónomos, etnógrafos, geopolíticos, historiadores, arqueólogos; y ha despertado el acuerdo y el asentimiento de los mismos campesinos andinos con quienes se ha conversado el tema, aunque para ellos se tratara de algo tan obvio que apenas necesita comentario. Me acuerdo de conversaciones con campesinos aymaras en el Altiplano occidental de La Paz; ellos me decían que por supuesto tenían islotes de tierras ahí abajo en los valles de Azapa y de Lluta en las costas de lo que hoy es el Norte Grande chileno. Como me explicaron, las comunidades del altiplano "siempre" habían disfrutado del acceso a determinadas tierras de maíz, y a guaneras específicas en la costa, adyacentes a su pedazo de cordillera. Las implicancias geopolíticas de esta constatación son obvias: la Cordillera debe imaginarse transversalmente, no -como por los europeos- desde el Norte hacia el Sur, o como una barrera entre la costa y la selva. Llevada a sus lógicas consecuencias, todos los campesinos de la Cordillera occidental podrían pretender a tener acceso a "su" costa, que en el caso de los habitantes de la moderna República de Bolivia sería desde Moquegua hasta Copiapó; aunque ningún político boliviano se haya atrevido a tomar el toro por las astas y poner este reclamo sobre la mesa de las negociaciones con Chile y el Perú.

Por otra parte, el eminente arqueólogo (y marisquero) del Norte chileno Lautaro Núñez -buen amigo de Murra y gran conocedor de los modos de pensamiento de la gente andina, además de partícipe, con estudios fundamentales sobre la trashumancia, en la creación del mismo concepto de la "verticalidad"- me decía, pensando en las construcciones de cartón y hojalata que hoy van llenando los desiertos del Norte Grande (todas sin cañerías de agua), que "siempre se ha intercambiado agua dulce por agua salada" ... Y sin embargo el Estado boliviano de aquel tiempo, ;se dedicaba a privatizar las aguas dulces de la Cordillera occidental por toda la frontera chilena ...!

Habiendo establecido el modelo del archipiélago vertical, Murra después insistió en la necesidad de buscar las limitaciones del mismo modelo, un reto irresistible a la investigación. Y las limitaciones fueron encontradas: en el norte, por Frank Salomon con el descubrimiento de los mindalaes ecuatorianos, ese gremio de mercaderes que trasportaban productos entre los pisos ecológicos y acudían a los qhatus, lugares donde se concentraban los productos de diferentes climas para ser intercambiados; por María Rostworowski con su énfasis sobre las relaciones "horizontales", sobre todo en la costa del Pacífico, provocando el debate sobre la relevancia del concepto de "mercado" en tiempos pre-hispánicos, y de su relación con el concepto de "intercambio institucionalizado" que preferían Murra y Polanyi (una versión andina del debate entre los "substantivistas y los "formalistas" de la antropología anglo-americana de aquel entonces); o en el sur, donde yo y otros estudiábamos cómo los desplazamientos de las llamas hacia ambos lados de la Cordillera de Lipez, para realizar el trueque de sal y algas (llullucha) altoandinos por el maíz de los valles, reemplazaron el control directo de las tierras de producción maicera que era parte del modelo de la verticalidad tal como se realizaba entre sus vecinos Karanqa y Qaraqara más al norte. De esta manera, Murra intentó encauzar la crítica hacia nuevas investigaciones. Y le gustaba imaginarlas, no como fruto de enfrentamientos y polémicas, sino como los pliegues de un abanico, donde uno puede sospechar -con cariño- que sería él quien estaría agitando el abanico.

John fue su propio peor enemigo en muchos aspectos. El conocía sus diablos internos, bebía en el sicoanálisis para superarlos, pero nunca pudo separarse de Cornell, que una vez le escuché asemejar a una teta de mamá que le alimentaba, aunque era también fuente de su aceptación como Full Professor y Professor Emeritus en el sistema académico norteamericano. Y sin embargo, durante sus últimos años, antes de inmovilizarse en un piso de Ithaca, iba por América Latina -a Lima, a Arica, a Santiago, a Sucre- buscando lugares donde había gente que le querían para quizás jubilarse allá ... Pensaba también en España, y aquí también había gente amiga -Andrés Guerrero y María Lourties en Madrid, Enriqueta Vila desde Sevilla-, que intentaban a animarle a que salga de Ithaca, y que venga a donde quizás se sentiría mejor.

Terminaré con un ejemplo más de aquel tipo de exageración que encierra una verdad y promueve una enseñanza. Vi hace poco, aquí en Barcelona, una película dirigida por María Eugenia Esparragosa, que comparaba la música de los negros venezolanos y la de los negros del Congo. En un momento se muestra a un grupo de músicos congoleses escuchando la música afro- 
americana y quedándose impresionados por las similitudes entre ésta y su propia música. “¿Como puede ser?", preguntaron; hasta que les fue recordado que muchos de sus antepasados habían ido a América ... “iAh sí!”, dijo un viejo, "es verdad”; y después, con una sonrisa pícara, entre orgullosa e irónica: "Sí, ¡nosotros hemos invadido a América!" La frase es brillante: se ve que al negro congolés no le interesa ir por la vida como víctima. Este hombre había transformado el trato de los esclavos en una migración voluntaria, logrando una soberbia inversión del "sentido común" de la historia. Transformó en gesto, ironía y sonrisa lo que podría haber sido motivo de protesta, herida y denuncia. Estoy seguro que a John, al gran actor, le hubiera encantado la exageración tan elocuente del músico africano, y la inversión de la agencia histórica que insinúa.

París y Barcelona, 2007

Notas

1 Agradezco a Frank Salomon el envío de estas citas, procedentes de sus apuntes tomados durante un curso de JVM intitulado "History of US Anthropology" (1971).

2 Tristan Platt, Thérèse Bouysse-Cassagne, Olivia Harris. Qaraqara-Charka. Mallku, Inka y Rey en la Provincia de
Charcas. Historia antropológica de una confederación aymara. Institut Français d'Études Andines / Plural editores / University of St. Andrews / University of London / Inter-American Foundation / Fundación Cultural del Banco Central de Bolivia. La Paz 2006. 
